\title{
ANALYSIS OF ANTIOXIDANT ACTIVITY, TOTAL PHENOLIC CONTENT AND TOTAL FLAVONOID CONTENT OF LANTANA CAMARA LEAVES AND FLOWERS
}

\author{
JIGISHA ANAND ${ }^{1 *}$, SHANU CHAUDHARY ${ }^{2}$, NISHANT RAI ${ }^{1}$ \\ ${ }^{1}$ Department of Biotechnology, Graphic Era (Deemed to be University), Dehradun - 248 002, Uttarakhand, India. ${ }^{2}$ Department of \\ Microbiology, Uttaranchal College of Science and Technology, Dehradun - 248 001, Uttarakhand, India. Email: jiggs21@gmail.com
}

Received: 23 November 2017, Revised and Accepted: 03 January 2018

\section{ABSTRACT}

Objective: The present study aims at screening phytochemicals present in Lantana camara leaves and flower extracts.

Methods: Methanolic extracts of leaves and flower of L. camara were prepared by the solvent extraction method. The preliminary qualitative photochemical analysis of leaves and flower extract was done following standard procedures. For quantitative phytochemical screening, total phenolic content (TPC), total flavonoid content (TFC), and free radical scavenging activity of L. camara was estimated.

Results: The preliminary qualitative analysis showed the presence of flavonoids, phenols, terpenoids, anthocyanins, carbohydrates, and proteins in the methanolic extracts of Lantana leaves and flower, while saponins, glycosides, and alkaloids were not detected in both the extracts. Quantitative assays were done for determination of TPC, TFC, and free radical scavenging activity of L. camara. The methanolic extract of Lantana flowers depicted highest TFC (15.76 $\pm 0.005 \mathrm{mg}$ of hydrated catechin equivalent $/ \mathrm{ml}$ of sample) and TPC (17 $\pm 0.005 \mathrm{mg}$ of Gallic acid equivalents equivalent/ml of sample), while both leaves and flower extracts revealed extortionately high 2, 2-diphenyl-1-picrylhydrazyl free radical scavenging activity.

Conclusion: The present work depicted that L. camara leaves and flowers are rich in antioxidant activity and have a promising application as nutraceuticals for herbal drug formulations.

Keywords: Lantana camara, 2, 2-diphenyl-1-picrylhydrazyl, Folin-Ciocalteu, Antioxidant activity.

(c) 2018 The Authors. Published by Innovare Academic Sciences Pvt Ltd. This is an open access article under the CC BY license (http://creativecommons. org/licenses/by/4. 0/) DOI: http://dx.doi.org/10.22159/ajpcr.2018.v11i4.23900

\section{INTRODUCTION}

Lantana camara is a popular ornamental garden plant and commonly known as wild sage or Lantana. It is a tropical origin plant and native to Central and Northern South America and Caribbean. L. camara is reported in Mexico, Florida, Trinidad, Jamaica, Brazil, Kenya, Uganda, Tanzania, and South Africa [1].

It is a woody straggling plant with small flower held in clusters (called umbels). The color usually is pink, white, yellow, violet, orange, and sometimes varying from white to red in various shades (Fig. 1). The leaves are arranged in opposite pairs and are broadly oval, rough with short hairs, with finely toothed edges along with a number of veins giving a wrinkled appearance. The leaves are 3-8 cm long and 3-6 cm wide, green in color. Leaves and stem are covered with rough hairs (Fig. 2).

L. camara is an important medicinal plant with several medicinal uses in the traditional medication system. It has been used to cure many health problems in different parts of the world [1]. The leaves have medicinal properties and exert a therapeutic effect against cuts, ulcers, catarrhal infection, tetanus, rheumatism, malaria, cancer, chicken pox, asthma, ulcer, swelling, eczema, tumor, high blood pressure, sores, measles, and fevers.

The whole plant infusion is used to cure bronchitis, and the powdered root in milk is given to children for stomachache and as a vermifuge. Lantana oil is used in the treatment of skin, itches, and as an antiseptic for wounds [2]. The fruits are useful in fistula, pustules, tumors, and rheumatism.

Different parts of L. camara are reported to possess essential oils, phenolic compounds, flavonoids, carbohydrates, proteins, alkaloids, glycosides, quinine, saponins, steroids, triterpenes, and tannin as major phytochemical groups $[3,4]$. These diversified phytochemicals attribute to multiple health potentials of plants and their extracts [5]. These phytoconstituents are used for the treatment of various human ailments and possesses wound healing, allelopathic, anthelmintic, anticancer, antifungal, nematostatic, insecticidal, and antihyperglycemic activity [6-9]. Thus, it is pertinent that these herbal sources are optimistic nutraceuticals and can have wide pharmacological application in herbal drug development.

To the best of our knowledge, flowers (pink turn yellow colored) of L. camara have not been much explored for their total phenolic content (TPC), total flavonoid content (TFC), and antioxidant activity. Thus, the aim of the present study was to assess TPC, TFC, and antioxidant activity of methanolic extract of $L$. camara leaves and flowers (pink turn yellow color) and comparing their pharmacological activity. The rationale for the present investigation was to evaluate active phytocompounds in leaves and flower extracts of $L$. camara which will assist in the future determination of their efficacy as a potent antimicrobial herbal drug against clinical and drug-resistant pathogens.

\section{MATERIALS AND METHODS}

\section{Collection of $L$. camara leaves and flowers}

L. camara leaves and flowers (yellow and pink colored) were collected from a nearby locality of Gujrara, Sahastradhara Road, Dehradun $\left(30^{\circ} 38^{\prime} 72.31^{\prime \prime} \mathrm{N}, 78^{\circ} 13^{\prime} 16.06^{\prime \prime} \mathrm{E}\right)$ and were authenticated at the Department of Botany, Uttaranchal College of Science and Technology, Dehradun. The leaves and flower samples have been indicated as Lantana leaves (LL) and Lantana flowers (LF), respectively. The LL and LF samples were thoroughly washed, dried, and ground into fine powder and were kept in sealed polyethylene bags in a refrigerator at $4^{\circ} \mathrm{C}$ 


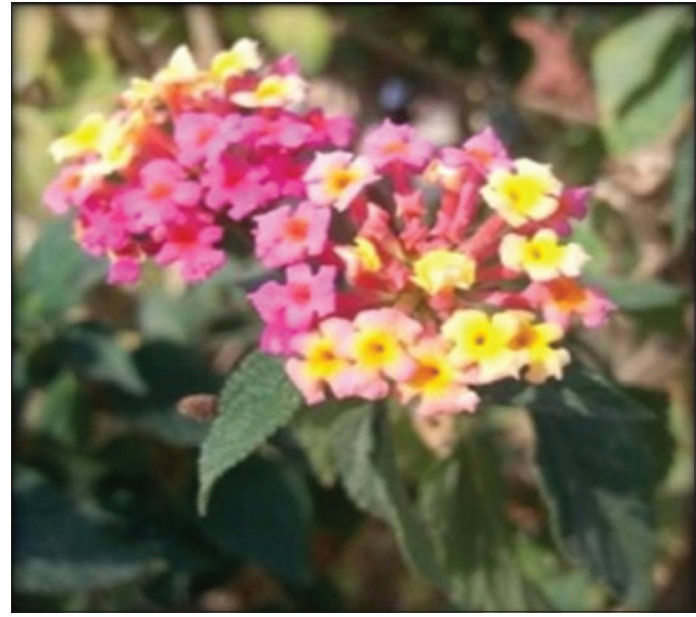

Fig. 1: Lantana camara flower

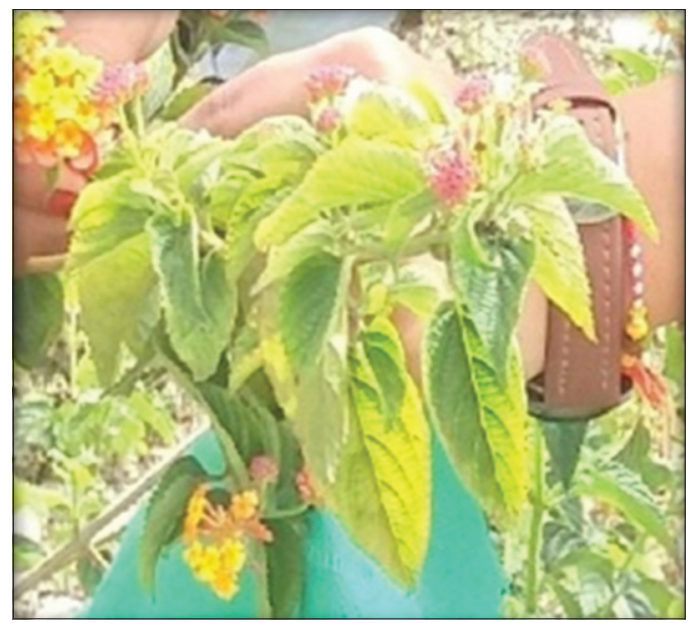

Fig. 2: Lantana camara leaves

\section{Preparation of extracts}

The leaves and flower extract was individually prepared in $70 \%$ methanol (plant: solvent ratio [1: 10]) following maceration technique. The crude extracts of LL and LF, left as a viscous mass was weighed and their respective percentage yield was evaluated. The extracts were stored at $4^{\circ} \mathrm{C}$ in a refrigerator [10].

\section{Preliminary qualitative phytochemical analysis}

Phytochemicals flavonoids, alkaloids, steroids, terpenoids, glycosides, saponins, catechol tannins, anthocyanin, carbohydrates, and amino acid were traced in the methanolic extract of LL and LF following standard procedures [11].

\section{Preliminary quantitative phytochemical analysis Determination of TFC}

The TFC was determined by thealuminum chloride colorimetric method. $100 \mu \mathrm{l}$ of the $1 \mathrm{mg} / \mathrm{ml}$ stock solution of LL sample was gently diluted with $400 \mu \mathrm{l}$ of distilled water in a test tube. Thereafter, the diluted sample was subsequently mixed with $30 \mu \mathrm{l}$ of $5 \% \mathrm{NaNO}_{2}$ solution and kept at rest. After $5 \mathrm{~min}$ of incubation, $30 \mu \mathrm{l}$ of $10 \% \mathrm{AlCl}_{3}$ was incorporated into the mixture and allowed to stand for another $5 \mathrm{~min}$. Thereafter, $20 \mu \mathrm{l}$ of $4 \% \mathrm{NaOH}$ was added, and the final volume of solution was made up to $1 \mathrm{ml}$ with distilled water. Absorbance of the mixture was immediately measured against blank at $510 \mathrm{~nm}$. The standard curve of hydrated catechin was used for quantification of $\mathrm{TFC}\left(\mathrm{R}^{2}=0.916\right)$ [12]. The test was repeated for LF sample $(1 \mathrm{mg} / \mathrm{ml})$. Duplicate measurements were taken. Results were expressed as milligram of catechin equivalents per gram of samples and calculated as hydrated catechin $\times \mathrm{V} / \mathrm{M}$ where, hydrated catechin equivalent $(\mathrm{mg} / \mathrm{ml}), \mathrm{V}=$ total volume of sample and $\mathrm{m}=$ weight of sample.

\section{Determination of TPC}

The TPC present in LL and LF extracts was assessed by following Folin-Ciocalteu Reagent (FCR) assay. A stock solution of methanolic extract of LL and LF (1 mg/ml) was prepared in methanol. The stock solution $(20 \mu \mathrm{l})$ was diluted in $80 \mu \mathrm{l}$ of water in a test tube. Then, 500 $\mu \mathrm{l}$ of FCR was added to the mixture and was kept for incubation in the dark at room temperature for $5 \mathrm{~min} .400 \mu \mathrm{l}$ of $7.5 \%$ sodium carbonate solution was incorporated into the mixture, agitated and left for further incubation for $30 \mathrm{~min}$ in the dark at room temperature. The test was repeated for LF sample as well. Absorbance of all the treated extracts was measured at $765 \mathrm{~nm}$ against blank using colorimeter. Water was used as blank while quantification of TPC was done on the basis of a standard curve of Gallic acid $\left(R^{2}=0.944\right)$ [13]. Measurements were carried in duplicates. Results were expressed as milligram of Gallic acid equivalents (GAE) per gram of samples and calculated as GAE $\times \mathrm{V} / \mathrm{M}$ where, $\mathrm{GAE}=$ Gallic acid equivalent $(\mathrm{mg} / \mathrm{ml}), \mathrm{V}=$ total volume of sample and $\mathrm{m}=$ weight of sample.

Determination of the Antioxidant Activity by 2-diphenyl-1-picrylhydrazyl (DPPH) assay

The antioxidant potential of both LL and LF extracts against DPPH free radical was assessed using DPPH free radical scavenging activity. The LL and LF solvent extracts (100 $\mu \mathrm{l} \mathrm{each)} \mathrm{were} \mathrm{separately} \mathrm{mixed} \mathrm{with}$ $1900 \mu \mathrm{l}$ of the DPPH solution and allowed to incubate for $2 \mathrm{~h}$ in the dark. Absorbance was measured against blank in duplicates at $515 \mathrm{~nm}$. Methanol was taken as blank while ascorbic acid was used as a standard for plotting of the calibration curve $\left(\mathrm{R}^{2}=0.919\right)$ [14].

The percentage scavenging effect was calculated as:

Scavenging rate $(\%)=\left[\left(A_{0}-A_{1}\right) / A_{0}\right] \times 100$, where, $A_{0}$ was the absorbance of the control (without extract), and $A_{1}$ was the absorbance in the presence of the extract.

\section{RESULTS}

\section{Data interpretation}

Statistical analysis was carried out using Windows Excel 2007. Experimental results were expressed as the mean \pm standard deviation (SD). The significance of screened TPC, TFC, and antioxidant activity was determined using one-way analysis of variance followed by $t$-test. The results were considered significant at $\mathrm{p} \leq 0.05$.

\section{Preparation of extracts}

Methanolic extracts of LL and LF were prepared, and their percentage yield was evaluated. Between the methanolic extract of LL and LF, maximum \% yield was depicted in LF extract (Table 1).

\section{Preliminary qualitative phytochemical analysis}

The qualitative phytochemical screening of solvent extracts of LL and LF indicated the presence of phenols, terpenoids, flavonoids, carbohydrates, amino acids, anthocyanin, and betacyanins while saponins, alkaloids, and glycosides were not detected in the test samples (Table 2).

\section{Preliminary quantitative phytochemical analysis}

There was a significant difference in TFC and TPC observed between LL extract and LF extract ( $p \leq 0.05)$; however, there was the non-significant difference in free radical scavenging activity of LL and LF extracts and both the extracts showed favorably higher percentage of antioxidant activity (Table 3).

The TFC in methanolic extracts of LL and LF was quantified from the standard calibration curve of hydrate catechins (Fig. 3). The TFC has been recorded highest in LF with a concentration of $15.76 \pm 0.005 \mathrm{mg}$ 
Table 1: Nature and color of methanolic extracts and their percentage yield

\begin{tabular}{lll}
\hline Methanolic extract & $\begin{array}{l}\text { Nature and color of } \\
\text { extract }\end{array}$ & \% yield \\
\hline LL & Lustrous thick, dark green & 57.53 \\
LF & Coal tar form, black & 33.48 \\
\hline
\end{tabular}

LL: Lantana leaves, LF: Lantana flowers

Table 2: Qualitative estimation of phytochemicals in solvent extracts of LL and LF

\begin{tabular}{|c|c|c|c|}
\hline S. No. & Qualitative test & Leaves extract & Flower extract \\
\hline & Carbohydrates & & \\
\hline \multirow[t]{3}{*}{1.} & Benedict's test & + & + \\
\hline & Fehling's test & + & + \\
\hline & Bar ford's test & + & + \\
\hline \multirow[t]{2}{*}{2.} & Protein & & \\
\hline & Biuret test & + & + \\
\hline 3. & Saponins & - & - \\
\hline 4. & Alkaloids & - & - \\
\hline 5. & $\begin{array}{l}\text { Anthocyanin and } \\
\text { betacyanins }\end{array}$ & + & + \\
\hline 6. & Flavonoids & + & + \\
\hline 7. & Glycosides & - & - \\
\hline 8. & Terpenoids & + & + \\
\hline 9. & Phenols & + & + \\
\hline
\end{tabular}

Where, + : Indicates presence of the phytocomponent and -: Indicates absence of the phytocomponent. LL: Lantana leaves, LF: Lantana flowers

hydrated catechin equivalent/g of sample $(\mathrm{p} \leq 0.05)$

The quantitative estimation depicted a significant difference in TPC of LL and LF extracts $(p \leq 0.05)$. Methanolic extract of LF showed higher TPC at a concentration of $17 \pm 0.005 \mathrm{mg}$ of $\mathrm{GAE} / \mathrm{g}$ of sample with reference to a standard curve (Fig. 4)

The antioxidant potential of LL and LF was quantified using the standard calibration curve of ascorbic acid (Fig. 5) and showed a nonsignificant $(\mathrm{p} \geq 0.05)$ difference in antioxidant potential of methanolic extract of LL and flower extracts.

\section{DISCUSSION}

The variation in the nature and solubility of plant secondary metabolites in different solvents contributes differences in percentage yield of the plant [15]. In the present study, we also observed variation in $\%$ yield of solvent extracts of LL and flowers.

The phytochemical review of Lantana has indicated the presence of quinones, terpenoids, flavonoids, steroids, and glycosides as the main class of components with relevant biological activity [16]. Our findings correlate with the previous studies in which flavonoids, terpenoids, phenols, carbohydrates, amino acids, and anthocyanins were reported to be present in Lantana while alkaloids, saponins, and glycosides were reported absent in solvent extracts of LL [17-19].

In comparison to the present observation, Kumar et al. have reported higher TFC and TPC in methanolic extracts of Lantana plant with pink turn yellow flower [20]. It is noteworthy that maceration time for extraction was longer in our study, which could have affected the extraction of flavonoids and phenolics in the extracts [21]

With respect to the free radical scavenging activity, the presence of higher polyphenolic compounds attributes in favorable reducing capability of plants and indicates their antioxidant potential [22-24]. In the present investigation, the quantitative phytochemical analysis of leaves and flower extracts of Lantana exhibited a substantial amount of TFC and TPC which could have significantly contributed to their

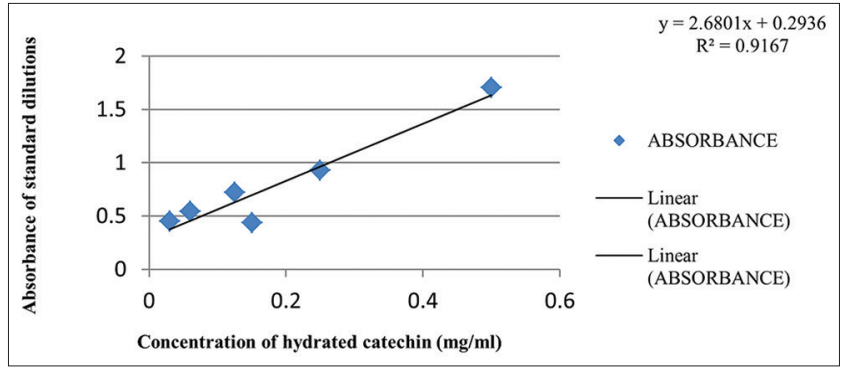

Fig. 3: Calibration curve of hydrated catechin as a reference for total flavonoid content

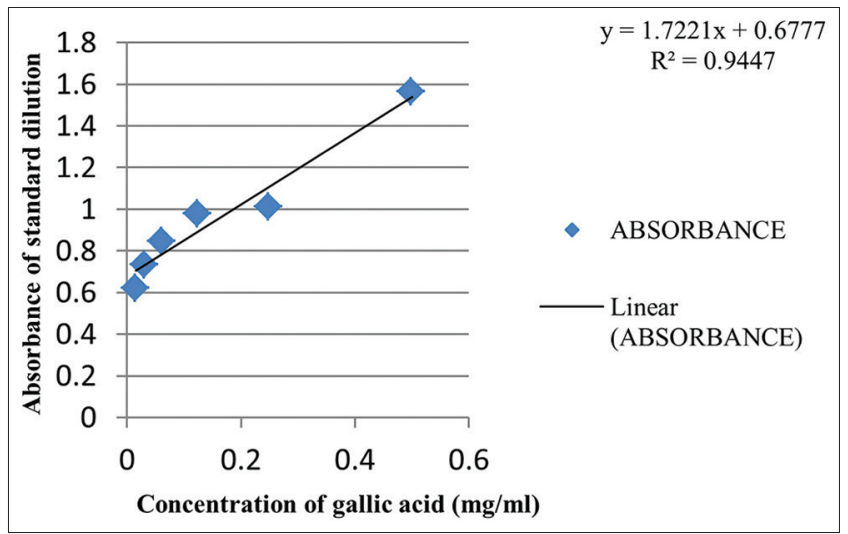

Fig. 4: Calibration curve of gallic acid as a reference for total phenolic content

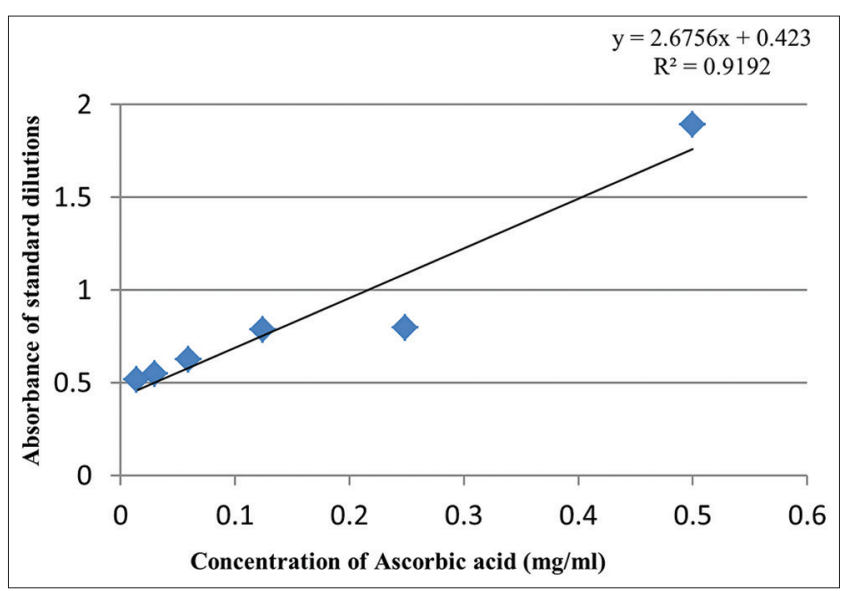

Fig. 5: Calibration curve of ascorbic acid for 2, 2-diphenyl-1picrylhydrazyl free radical scavenging activity

higher free radical scavenging activity. Our findings are consistent with those reported by Esmaeili et al., who has also reported that there is the existence of a strong relationship between phytochemical contents and free radical scavenging potential of natural resources [25].

The presence of flavonoids, phenolics compounds, and antioxidant activities in L. camara extracts (LL and LF) signify broad-spectrum antibacterial potential and confer their implementation as alternative therapeutic agents against pathogenic as well as antibiotic-resistant bacteria [26].

\section{CONCLUSION}

The present investigation concludes that the LL and flowers have rich antioxidant efficacy with promising nutraceuticals potency which 
Table 3: Quantitative estimation of TFC, TPC, and free radical scavenging activity in methanolic extracts of LL and LF

\begin{tabular}{llll}
\hline Extracts & $\begin{array}{l}\text { TFC (mg of hydrated catechin equivalent/ml } \\
\text { of sample) }\end{array}$ & $\begin{array}{l}\text { TPC (mg of GAE equivalent/ml of } \\
\text { sample) }\end{array}$ & $\begin{array}{l}\text { DPPH free radical scavenging } \\
\text { activity (\%) }\end{array}$ \\
\hline LL & $11.5 \pm 0.056^{\mathrm{a}}$ & $9.16 \pm 0.016^{\mathrm{b}}$ & $86.3 \pm 0.354^{\mathrm{c}}$ \\
LF & $15.76 \pm 0.005^{\mathrm{a}}$ & $17 \pm 0.005^{\mathrm{b}}$ & $87.2 \pm 0.003^{\mathrm{c}}$ \\
\hline
\end{tabular}

$\mathrm{a}, \mathrm{b}$, and c represent significant difference in student's $t$-test. Values are expressed as mean $\pm \mathrm{SD}(\mathrm{n}=2)$. For, TFC and TPC, means in the same column with same letters are significantly different ( $\mathrm{p} \leq 0.05$ ), while for DPPH free radical scavenging activity, means in the same column with same letters are statistically non-significant ( $\geq 0.05$ ). Row (degree of freedom=3), column (degree of freedom=1). LL: Lantana leaves, LF: Lantana flowers, TFC: Total flavonoid content, TPC: Total phenolic content, GAE: Gallic acid equivalent, DPPH: 2, 2-diphenyl-1-picrylhydrazyl, SD: Standard deviation

confers its pharmacological application in herbal drug development against debilitating diseases.

\section{ACKNOWLEDGMENT}

We extend our gratitude to the Department of Biotechnology, Graphic Era University, for their consistent encouragement throughout the research work. Furthermore, we would like to acknowledge Ms. Shanu Choudhary, postgraduate student, Department of Microbiology, Uttaranchal College of Science and Technology, Dehradun, who has equally contributed in conducting the experiments.

\section{AUTHOR'S CONTRIBUTION}

JA designed the study and wrote the manuscript. SC and JA performed the experiments. JA and NR analyzed and verified the data.

\section{CONFLICT OF INTEREST}

The author's declares no conflict of interest.

\section{ABBREVIATIONS}

TFC- Total flavonoid content

TPC- Total phenolic content

GAE- Gallic acid equivalent

DPPH- 2, 2-diphenyl-1-picrylhydrazyl

LL- Lantana leaves

LF- Lantana flowers

FCR- Folin ciocalteu reagent

SD- Standard deviation

ANOVA- Analysis of variance

\section{REFERENCES}

1. Bevilacqua AH, Suffredini IB, Romoff P, Lago JH, Bernardi MM. Toxicity of apolar and polar Lantana camara L. crude extracts in mice. Res Vet Sci 2011;90:106-15.

2. Khare CP. Indian Medicinal Plants - An Illustrated Dictionary. Berlin: Springer; 2007.

3. Venkatachalam T, Kumar VK, Selvi PK, Maske AO, Anbarasan V, Kumar V. Antidiabetic activity of Lantana camara Linn fruits in normal and streptozotocin-induced diabetic rats. J Pharma Res 2011;4:1550-2.

4. Kalita S, Kumar G, Karthik L, Rao KV. A review on medicinal properties of Lantana camara Linn. Res J Phar Tech 2012;5:711-5.

5. Ikram ME, Itmad AE, Jihad HE, Eiman SE. A comparative study of chemical composition of Acacia seval stem, stem wood and stem bark dry distillates used by sudaneses women as cosmetic and medicine. Int J Phar Pharma Sci 2017;9:218-24

6. Ahmad F, Rather MA, Siddiqui MA. Nematicidal activity of leaf extracts from Lantana camara L. against Meloidogyne incognita (kofoid and white) chitwood and its use to manage roots infection of Solanum melongena L. Braz Arch Biol Technol 2010;53:538-48.

7. Choyal R, Sharma S. Evaluation of allelopathic effects of Lantana camara (Linn) on regeneration of Pogonatum aloides in culture media. Asian J Plant Sci Res 2011;1:41-8.
8. Goswami-Giri AS, Ingawale GS. Lantana camara (Linn): Green Informatics Approach. Bionano Frontier Eco Revolution 2012. p. 291-94

9. Sunila AV, Murugan K. Variation in phenolics, flavonoids at different stages of fruit development of Pouteria Campechiana (kunth) baehni and its antioxidant activity. Int J Pharm Pharm Sci 2017;9:70-5.

10. Anand J, Upadhayaya B, Rawat P, Rai N. Biochemical characterization and pharmacognostic evaluation of purified catechins in green tea (Camellia sinensis) cultivars of India. Biotechnology 2015;5:285-94.

11. Santhi S, Sengottuvel R. Qualitative and quantitative phytochemical analysis of Moringa concanensis nimmo. Int J Curr Microbiol App Sci 2016;5:633-40

12. Baba SA, Malik AA. Determination of total phenolic and flavonoid content, antimicrobial and antioxidant activity of a root extract of Arisaema jacquemontii blume. J Taibah Univ Sci 2015;9:449-54.

13. Sen S, De B, Devanna N, Chakraborty R. Total phenolic, total flavonoid content, and antioxidant capacity of the leaves of Meyna spinosa Roxb., an Indian medicinal plant. Chinese J Nat Med 2013;11:149-57.

14. Villano D, Fernandez-Pachon MS, Moya ML, Troncoso AM, Garc1a-Parrilla MC. Radical scavenging ability of polyphenolic compounds towards DPPH free radical. Talanta 2007;71:230.

15. Al-Younis NK, Abdullah $\mathrm{AF}$. Isolation and antibacterial evaluation of plant extracts from some medicinal plants in Kurdistan region. J Duhok Univ 2009;12:250-5

16. Sousa EO, Costa JG. Genus Lantana: Chemical aspects and biological activities. Braz J Pharma 2012;22:1155-80

17. Naz R, Bano A. Phytochemical screening, antioxidants and antimicrobial potential of Lantana camara in different solvents. Asian Pac J Trop Dis 2013;3:480-6.

18. Sushama RR. Preliminary phytochemical screening of Lantana camara L., a major invasive species of Kerala, using different solvents. Ann Plant Sci 2017;6:1794-98.

19. Hemalatha P, Elumalai D, Janaki A, Babu M, Velu K, Velayutham K, et al. Larvicidal activity of Lantana camara aculeata against three important mosquito species. J Entomol Zoo Stud 2015;3:174-81.

20. Kumar S, Sandhir R, Ojha S. Evaluation of antioxidant activity and total phenol in different varieties of Lantana camara leaves. BMC Res Notes 2014; 7:560.

21. Margeretha I, Suniarti DF, Herda E, Masud ZA. Optimization and comparative study of different extraction methods of biologically active components of Indonesian Propolis trigona spp. J Nat Prod 2012;5:233-42

22. Rao AS, Reddy SG, Babu PP, Reddy AR. The antioxidant and antiproliferative activities of methanolic extracts from Njavara rice bran. BMC Complement Altern Med 2010;10:4

23. Cathrine L, Nagarajan NP. Preliminary phytochemical analysis and antibacterial activity of leaf extracts of Vitex leucoxylon L.F. Int J Curr Pharma Res 2010;3:71-3.

24. Sreeja S, Regi RK. Qualitative and quantitative phytochemical analysis and dpph radical scavenging activity of different extracts of flower of Bauhinia acuminata Linn. Int J Curr Pharma Res 2017:9:23-6.

25. Esmaeili AK, Taha RM, Mohajer S, Banisalam B. Antioxidant activity and total phenolic and flavonoid content of various solvent extracts from in vivo and in vitro grown Trifolium pretense L. (Red Clover). Biomed Res Int 2015;2015:11

26. Salada JT, Balala LM, Vasquez EA. Phytochemical and antibacterial studies of Lantana camara 1. leaf fraction and essential oil. Int J Sci Res Pub 2015;5:1-5. 